\title{
Factors associated with feeding practices among Brazilian children aged 12 to 23 months old
}

\section{Adriana Gama Rebouças 1}

https://orcid.org/0000-0002-3150-9526

Ítalo de Macedo Bernardino 2

https://orcid.org/0000-0003-4750-5666

Emiliane Rodrigues Dutra 3

https://orcid.org/0000-0002-6408-3269

José Carlos Pettorossi Imparato 4

https://orcid.org/0000-0002-1990-2851
Danilo Antonio Duarte 5

iD https://orcid.org/0000-0002-2291-5434

Flávia Martão Flório 6

https://orcid.org/0000-0001-7742-0255

1,4,5 Departamento de Odontopediatria. Faculdade São Leopoldo Mandic. Campinas, SP, Brasil.

2 Departamento de Odontologia. Universidade Estadual da Paraíba. Campina Grande, PB, Brasil.

3,6 Departamento de Saúde Coletiva. Faculdade São Leopoldo Mandic. Rua José Rocha Junqueira, 13. Ponte Preta. Campinas, SP, Brasil. CEP: 13.045-755. E-mail: flavia.florio@slmandic.edu.br

\begin{abstract}
Objectives: a quantitative analytical cross-sectional study aimed to identify demographic characteristics to access health services and housing conditions in relation to inadequate feeding practices among Brazilian children from 12 to 23 months of age.

Methods: the analysis of the feeding practices (consumption of recommended food groups) of 2541 Brazilian children (aged 12-23 months old) was performed using data from the Pesquisa Nacional de Saúde 2013 (National Health Survey). Descriptive and multivariate statistics used the Decision Tree Analysis based on CHAID (Chi-squared Automatic Interaction Detector) algorithm, as well as hierarchically adjusted Poisson regression analyses were performed. The variables were entered in a hierarchical model at distal (demographic), intermediate (access to health) and proximal (housing conditions) levels.

Results: the results showed a high prevalence of sugar consumption (85.5\%; $C 195 \%=83.7-87.2)$ and highlighted inadequate feeding practices among non-white children $(p=0.001)$, resident in the North $(p<0.001)$ and Northeast $(p=0.010)$ of Brazil and in towns in the countryside $(p<0.001)$ presented feeding practices that were not recommended for consumption in the food groups.

Conclusions: non-white children, who lived in the North and Northeast regions of Brazil and in the countryside, which are known to be more socioeconomically vulnerable, were more likely to experience inadequate feeding practices.
\end{abstract}

Key words Complementary feeding, Inequality in Health, Child health, Brazil

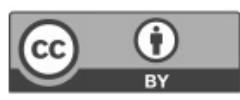




\section{Introduction}

Food introduction (FI) period begins in the sixth month of a baby's life, with the end of exclusive breastfeeding, which from this point onwards is complemented by a choice of food from different food groups (avoiding those with added sugar) to meet all the child's nutritional needs.1,2 Performed slowly and gradually, FI allows children, at 12 months of age, to consume the same meals as the rest of the family, provided they are not prepared with excess seasoning. 1 This phase of feeding, which continues up to the age of 24 months, occurs during a child's period of rapid growth and development, in which they are susceptible to nutritional deficiencies and/or excesses and during which there are strong changes in the diet, exposing to new food, flavors and eating experiences. ${ }^{3}$

To ensure the supply of nutrients, the Ministry of Health (MS) recommends different food groups cereals and tubers, vegetables and fruit, meat and eggs, grains and milk - are included in the children's daily diet in the FI phase. ${ }^{1}$ Similarly, added sugars and processed and ultra-processed food should be avoided 1 as these, combined with the low consumption of fruit and vegetables, increase the risk of obesity, cardiovascular disease, high blood pressure and the most prevalent non-communicable disease in the world today, tooth decay.2,4

The causality between a cariogenic diet and tooth decay is well established, 4 with the World Health Organization (WHO) suggesting that the intake of free sugars should be reduced to less than $10 \%$ of the total energy intake in children and adults' diets. ${ }^{2}$

Food education is a complex and continuous process. Although it originates in early childhood, food preferences from this period are associated with preferences at older ages. ${ }^{5}$ It has been shown that the quality of feeding practices is associated with socioeconomic level ${ }^{6}$ and that inadequate FI is associated with a lower monthly income and level of maternal schooling, 7,8 as well as ethnicity (AfroAmericans $^{9}$ and hispanics ${ }^{10}$ ), lack of postnatal care, ${ }^{11}$ lack of access to mass media ${ }^{11}$ and the child having an older sibling or a caregiver other than his or her parent. 12 This situation was identified in countries such as Tanzania, ${ }^{11}$ the USA, ${ }^{9}$ France 12 and Brazil, notably in city districts in the South of the country, ${ }^{8}$ and in Maceió, in the Northeast of Brazil. ${ }^{7}$

Irrespective of the existing recommendations and guidelines on healthy eating, especially for children under the age of two, the quality of diet of Brazilian children deviates greatly from what is considered ideal, 13 and despite advice to avoid adding sugar to food and sugary food, $60.8 \%$ of the children under two years of age consume cookies and cakes and $32.3 \%$ drink soft drinks or artificial juices. ${ }^{14}$

The Pesquisa Nacional de Saúde (PNS) (National Health Survey), performed in Brazil in 2013, evaluated the types of food consumed by children aged under two. However, no study, up to now, has used this data to assess whether children's feeding practices include all the different recommended food groups. Therefore, objective of the present study was to identify demographic characteristics, access to health services and housing conditions in relation to feeding practices among Brazilian children aged 12 to 23 months old.

\section{Methods}

A cross-sectional, analytical study, of a quantitative nature, was carried out using secondary data from the most recent Pesquisa Nacional de Saúde (PNS) (National Health Survey) carried out in Brazil.15

The PNS is an integral part of the IBGE Sistema Integrado de Pesquisas Domiciliares (SIPD) (Integrated Home Survey System) and uses the master sample of this system, representing Brazil, its macro-regions, urban and rural population and capitals. Data collection was carried out in homes from August 2013 to February 2014, based on three-stage cluster sampling. A total of 60,202 adults were interviewed and the non-response rate was $8.1 \% .15$

The data collection of the PNS was based on different questionnaire modules to investigate the characteristics of the households and their residents, in addition to gathering the individual data of the eligible resident. The present study included 2,541 children aged between 12 and 23 months whose families answered Module L of the questionnaire, which contained specific questions for this age group. 14

The dependent variable of the present study was inadequate feeding practices, that is, when the recommended food group intake was not fully attained for the children of the studied age group. To evaluate the food groups included in the children's daily diet, the answers to question 17 of module $\mathrm{L}$ of the questionnaire were used: "Can you tell me which of this food _ were eaten or drunk between yesterday morning and this morning?", to which the answer was yes or no. The following food was evaluated: breast milk, other milk or milk products; fruit or natural fruit juice; greens/vegetables; beans or other legumes; meat or eggs; potato and other tubers and 
roots; cereals and derivatives. The questionnaire did not differentiate between whether the food was consumed naturally, processed or ultra-processed.

Based on the responses to the questionnaire and considering the recommendations for breastfeeding and non-breastfeeding children were available in the Ministry of Health ${ }^{1}$ Guidebook 33 (a recommendation in effect during the application period of the questionnaire) the diets were classified as: adequate feeding practices, where the recommended food group intake has been fully achieved, with at least one food item from each recommended food group, and inadequate feeding practices, where the recommended food group intake has not been attained. ${ }^{1}$ The consumption of meat or supplementation with iron was considered as guaranteeing the intake of this nutrient.

In addition to the assessment of full compliance with the recommended food group intake, the prevalence of sugar consumption was assessed. Children who consumed processed food and ultra-processed food: cookies, biscuits, cakes, sweets, candies, artificial juices and soft drinks or other food with sugar were identified as sugar consumers. 1

The independent variables selected were classified according to the theoretical hierarchical model proposed by Victora et al.,16 which recognizes the existence of the proximal, intermediate or distal factors associated with the outcome, with distal factors considered to influence proximal factors, measuring effect, and controlling possible confounding factors. This approach includes a primary model containing the variables from the most distal level. At this level, the covariables associated with the outcome of $p<0.25$ were included in the next level, and so on, until the level of the most proximal covariate was reached. For the distal level, demographic characteristics were selected (sex, skin color, region in Brazil, area of residence and type of area of residence); the intermediate level included the characteristics to access health services (health insurance, health status of the child as reported by the respondent, medical appointment, dental appointment, location where growth is monitored, registration at family health unit, visit of the community health agent), and the proximal level, with housing conditions (number of residents per room, status of resident at home, predominant material of house walls, water supply at the residence, water used for drinking, residence with or without kitchen, television, microwave and access to internet) as shown in Figure 1. The composition of the levels as well as the order of entry into the hierarchical model were based on previous studies, including factors known to be associated with the quality of the diet.612

The IBM SPSS Statistics (version 20.0; Armonk, NY: IBM Corp. USA) and STATA (version 15.0; StataCorp., College Station, USA) software packages were used for analysis, taking into account the sample weightings from the complex sample design. Initially, a descriptive statistical analysis was carried out in order to characterize the sample. Pearson's chi-square test with second-order Rao-Scott corrections was used to identify associations between feeding practices and demographic characteristics, related to access to health services and housing conditions.

To assess the association between the outcome (inadequate feeding practices) and the independent variables (demographic characteristics, access to health services and those related to housing conditions), multivariate decision tree analysis was performed using the CHAID (Chi-squared Automatic Interaction Detector) algorithm to characterize the qualitative aspect of the children's diet.17,18 For the decision tree analysis, the explanatory variables which obtained $p<0.25$ in the bivariate analysis or were considered epidemiological determinants were incorporated into the multivariate model using the CHAID algorithm to characterize the children's feeding practices.

Subsequently, hierarchically adjusted Poisson regression analysis, considered a traditional statistical method for cross-sectional epidemiological studies with binary results, the measure of association with the odds ratio (OR), was performed.

The order of insertion of the variables in the hierarchical model is illustrated in Figure 1. At this level, the covariables associated with the outcome of $p<0.25$ were included in the next level, and so on, until the level of the most proximal covariate was reached. Only variables with $p<0.05$ remained in the final model, since the retention of other covariates in this model can alter the estimates. The same criterion was adopted in the final model of the decision tree.

The present study was exempted from the Ethics Committee of the Faculdade São Leopoldo Mandic, as it uses secondary data from the PNS, approved by the National Commission for Ethics in Research under the Opinion document N. 328.159, dated June $26,2013.15$ 


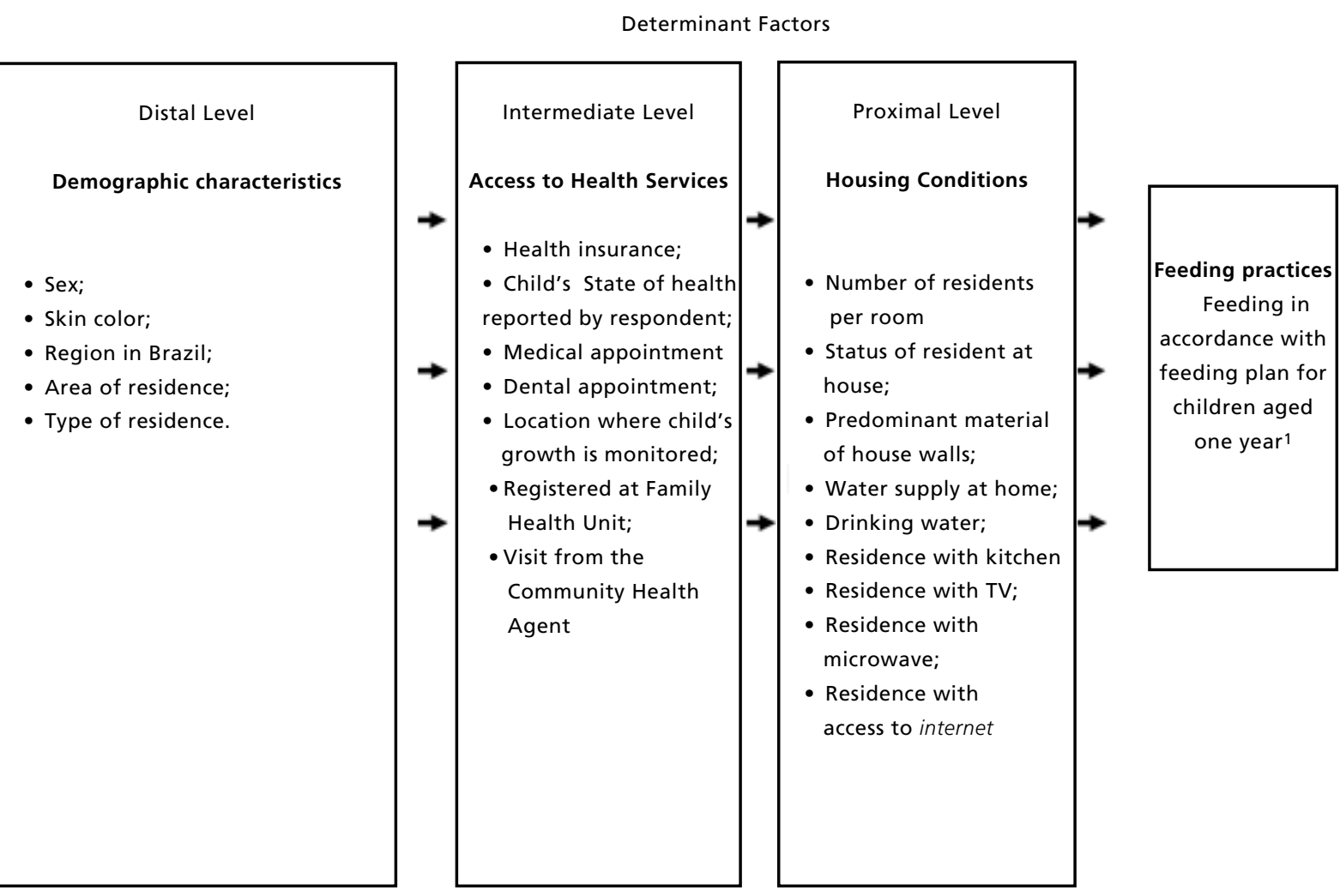

Brasil (2012).1

\section{Results}

A total of 2,541 children were evaluated and their characteristics are described in Table 1. The analysis of weighted frequencies showed that most were nonwhite and lived in the Northeast of Brazil. It can be observed that of the food recommended for daily intake, milk was the most prevalent, while vegetables were the least; there was a high prevalence of consuming sugary food and those unsuitable for the age group studied; most children were not covered by health insurance, and although $65 \%$ had their growth and development monitored in public health services, only half of the households received a visit from a community health agent and $8.3 \%$ did not receive any follow-up care. Most households had walls constructed with suitable material and appliances such as a refrigerator and television, while around a third of those had assessed to untreated water.
The bivariate analysis (Table 2) shows that sociodemographic variables, access to health services and those related to housing conditions were associated with the outcome.

Table 3 shows the results of the hierarchically adjusted Poisson regression analysis. The factors that remained in the final model were region in Brazil $(p<0.05)$, type of residence $(p<0.05)$, skin color $(p<0.05)$ and the last medical appointment $(p<0.05)$. Children who lived in the North or Northeast regions of the country, mostly in the countryside, were non-white and whose last medical appointment was more than a year ago were more likely to have inadequate feeding practices.

Figure 2 shows the results of the Decision Tree multivariate analysis (CHAID) for the feeding practices among Brazilian children aged 12-23 months old were adjusted for the investigated factors. Based on the final model, the factors associated with the outcome were: region in Brazil $(p<0.05)$, type of 
Distribution of Brazilian children aged 12-23 months old according to dietary and demographic characteristics, access to health services and housing conditions. Brazil, 2013-2014.

\begin{tabular}{|c|c|c|c|}
\hline Variables & $\mathrm{Na}$ & $\% b$ & $\mathrm{Cl} 95 \% \mathrm{~b}$ \\
\hline \multicolumn{4}{|c|}{ Food characteristics } \\
\hline \multicolumn{4}{|c|}{ Consumes food with sugar } \\
\hline Yes & 2158 & 85.5 & $83.7-87.2$ \\
\hline No & 383 & 14.5 & $12.8-16.3$ \\
\hline \multicolumn{4}{|c|}{ Feeding practice } \\
\hline Adequate & 1238 & 51.2 & $48.8-53.7$ \\
\hline Inadequate & 1303 & 48.8 & $46.3-51.2$ \\
\hline \multicolumn{4}{|l|}{ Milk } \\
\hline No & 121 & 4.5 & $3.6-5.6$ \\
\hline Yes & 2420 & 95.5 & $94.4-96.4$ \\
\hline \multicolumn{4}{|l|}{ Fruit } \\
\hline No & 491 & 17.9 & 16.1-19.9 \\
\hline Yes & 2050 & 82.1 & $80.1-83.9$ \\
\hline \multicolumn{4}{|c|}{ Vegetables/Legumes } \\
\hline No & 771 & 28.7 & $26.5-30.9$ \\
\hline Yes & 1770 & 71.3 & $69.1-73.5$ \\
\hline \multicolumn{4}{|l|}{ Grains } \\
\hline No & 554 & 20.0 & $18.1-22.0$ \\
\hline Yes & 1987 & 80.0 & $78.0-81.9$ \\
\hline \multicolumn{4}{|l|}{ Cereal/tubers } \\
\hline No & 330 & 11.5 & $10.1-13.1$ \\
\hline Yes & 2211 & 88.5 & $86.9-89.9$ \\
\hline \multicolumn{4}{|c|}{ Iron consumption } \\
\hline No & 295 & 10.5 & $9.1-12.0$ \\
\hline Yes & 2246 & 89.5 & $88.0-90.9$ \\
\hline
\end{tabular}

Demographic characteristics

Sex

Male

Female

Skin color

White

Non-white

Region in Brazil

North

Northeast

Midwest

Southeast

South

Area of residence

Urban

Rural

Type of residence

State Capital/Metropolitan Region

Rural region of state
1293

1248

1055

1486

744

786

303

461

247

1980

561

1531

1010
53.0

47.0

43.7

56.3

19.4

36.0

16.2

17.4

11.0

79.8

20.2

58.4

41.6
50.5-55.4

44.6-49.5

41.2-46.1

53.9-58.8

17.8-21.2

33.7-38.5

14.3-18.2

$15.6-19.3$

9.5-12.6

77.7-81.7

18.3-22.3

$55.9-60.8$

39.2-44.1

continue

\footnotetext{
a Unweighted estimates; b Weighted estimates considering complex sampling plan.
} 
Table 1

Distribution of Brazilian children aged 12-23 months old according to dietary and demographic characteristics, access to health services and housing conditions. Brazil, 2013-2014.

\begin{tabular}{|c|c|c|c|}
\hline Variables & $\mathrm{Na}$ & $\% \mathrm{~b}$ & $\mathrm{Cl} 95 \% \mathrm{~b}$ \\
\hline \multicolumn{4}{|l|}{ Access to health care services } \\
\hline \multicolumn{4}{|l|}{ Health insurance } \\
\hline Yes & 598 & 25.8 & $23.7-28.0$ \\
\hline No & 1943 & 74.2 & $72.0-76.3$ \\
\hline \multicolumn{4}{|c|}{ Child's health status as reported by the respondent } \\
\hline Very good or good & 2247 & 89.1 & $87.5-90.5$ \\
\hline Fair, poor or very poor & 294 & 10.9 & 9.5-12.5 \\
\hline \multicolumn{4}{|l|}{ Last medical appointment } \\
\hline$<1$ Year & 2307 & 92.1 & $90.6-93.3$ \\
\hline$>1$ Year & 162 & 5.6 & $4.6-6.8$ \\
\hline Never & 72 & 2.3 & $1.7-3.2$ \\
\hline \multicolumn{4}{|c|}{ Number of medical appointments in the last 12 months } \\
\hline 0 to 1 appointment & 664 & 24.7 & $22.6-26.9$ \\
\hline 2 to 6 appointments & 1287 & 51.8 & $49.3-54.3$ \\
\hline$\geq 7$ appointments & 590 & 23.5 & $21.4-25.6$ \\
\hline \multicolumn{4}{|l|}{ Has child been to the dentist } \\
\hline Yes & 452 & 17.5 & 15.7-19.4 \\
\hline No & 2089 & 82.5 & $80.6-84.3$ \\
\hline \multicolumn{4}{|l|}{ Where is the child's growth monitored } \\
\hline Private or company clinic & 548 & 23.8 & $21.7-26.0$ \\
\hline Public hospital, polyclinic or health unit & 1694 & 65.4 & $63.0-67.7$ \\
\hline Other & 69 & 2.5 & $1.8-3.5$ \\
\hline No follow-up monitored & 230 & 8.3 & $7.0-9.7$ \\
\hline \multicolumn{4}{|c|}{ Is household registered at the Family Health Unit } \\
\hline Yes & 1471 & 59.6 & $57.2-62.0$ \\
\hline No & 1070 & 40.4 & $38.0-42.8$ \\
\hline \multicolumn{4}{|c|}{ Have you received visits from a Community Health Agent } \\
\hline Yes & 1245 & 51.0 & $48.6-53.5$ \\
\hline No & 1296 & 49.0 & 46.5-51.4 \\
\hline
\end{tabular}

Housing conditions

Number of residents per room (median $=0.8$ )

$\leq 0.8$

$>0.8$

tatus of resident at home

Child of parent/guardian and spouse

Child or stepchild of parent/guardian only

Grandchild or great-grandchild

Other

Predominant material of the house walls

Masonry with cladding + suitable wood

Finished wood / straw / rammed earth / other

Water supply at home

General network

a Unweighted estimates; b Weighted estimates considering complex sampling plan. 
Distribution of Brazilian children aged 12-23 months old according to dietary and demographic characteristics, access to health services and housing conditions. Brazil, 2013-2014.

\begin{tabular}{|c|c|c|c|}
\hline Variables & $\mathrm{Na}$ & $\%$ b & $\mathrm{Cl} 95 \% \mathrm{~b}$ \\
\hline \multicolumn{4}{|l|}{ Water used for drinking } \\
\hline \multicolumn{4}{|c|}{ Treated (mineral, boiled filtrate or other home } \\
\hline treatment) & 1642 & 66.6 & $64.2-68.8$ \\
\hline Untreated (without home treatment) & 899 & 33.4 & $31.2-35.8$ \\
\hline \multicolumn{4}{|l|}{ Residence with kitchen } \\
\hline Yes & 2407 & 96.2 & $95.3-97.0$ \\
\hline No & 134 & 3.8 & $3.0-4.7$ \\
\hline \multicolumn{4}{|l|}{ Residence with television } \\
\hline Yes & 2427 & 96.7 & $95.7-97.4$ \\
\hline No & 114 & 3.3 & $2.6-4.3$ \\
\hline \multicolumn{4}{|l|}{ Residence with microwave } \\
\hline Yes & 988 & 40.5 & $38.1-43.0$ \\
\hline No & 1553 & 59.5 & $57.0-61.9$ \\
\hline \multicolumn{4}{|l|}{ Residence with internet access } \\
\hline Yes & 888 & 36.3 & $33.9-38.7$ \\
\hline No & 1653 & 63.7 & $61.3-66.1$ \\
\hline
\end{tabular}

a Unweighted estimates; b Weighted estimates considering complex sampling plan.

residence $(p<0.05)$, skin color $(p<0.05)$, internet access $(p<0.05)$, water used for drinking $(p<0.05)$ and number of residents per room $(p<0.05)$. Three patterns could be identified for the propensity of inadequate feeding practices: 1) children from the North of Brazil, from regions in the countryside of the States and without internet access at home; 2) children from the Northeast, from regions in the rural areas of the States and without adequate water for consumption at home; 3) children from the Southeast, South and Midwest regions, with internet access at home, and were white.

\section{Discussion}

The results of the present study, which are representative for Brazilian children aged 12-23 months old, suggest that according to the decision tree model in the region of the country and the area of residence, skin color, access to internet, drinking water and the number of residents per room were associated within adequate feeding practices, which do not meet the recommendation of the Ministry of Health that food from different food groups should be consumed on a daily basis.

Almost half of the children assessed did not consume food from every food group, as recommended by the Ministry of Health. 1 Vegetables/legumes and grains were the food types most likely not to be consumed, while there was a higher exposure to processed and ultra-processed foods with an extremely high prevalence $(85.5 \%)$ of food intake with sugar. Babies have an innate preference for sugar and salty tastes and do not like bitter tastes. ${ }^{3}$ While changing these innate taste preferences is impossible, parents can modify subsequent preferences by offering complementary food without added sugar or salt, and by introducing a variety of flavors, including bitter green vegetables, in a timely manner. ${ }^{3}$

The quality of the food intake of Brazilian children was shown to be inadequate in a previous study 19 which found that $10.6 \%$ and $20.4 \%$ of the daily energy consumption came from processed and ultra-processed food, respectively, and concluded that reducing the consumption of this type of food is a natural form of promoting healthy eating in Brazil. Despite the implementation of several food and nutrition strategies - the Rede Amamenta Brasil20 (Brazilian Breastfeeding Network), the Estratégia Nacional para Alimentação Complementar Saudável21 (National Strategy for Complementary Healthy Eating) and the Estratégia Amamenta e Alimenta Brasil22 (Brazil Breastfeeding and Food Strategy) - studies have shown that inadequate practices for introducing complementary feeding remain. 7,8 The ineffectiveness of the programs to promote healthy eating at childhood in Brazil has already been related to the precarious working conditions of health teams in a context being unfa- 
Table 2

Bivariate analysis between the characterization of feeding practice and demographic characteristics, access to health services and housing conditions of Brazilian children aged 12-23 months old. Brazil, 2013-2014.

\begin{tabular}{|c|c|c|c|c|c|c|c|c|}
\hline \multirow[t]{3}{*}{ Variables } & \multicolumn{6}{|c|}{ Dietary practice } & \multirow[t]{3}{*}{ PR $R_{\text {Gross }}(\mathrm{Cl} 95 \%)$} & \multirow[t]{3}{*}{ pa } \\
\hline & \multicolumn{2}{|c|}{ Adequate } & \multicolumn{2}{|c|}{ Inadequate } & \multicolumn{2}{|c|}{ Total } & & \\
\hline & $\mathrm{n}$ & $\%$ & $\mathrm{n}$ & $\%$ & $\mathrm{n}$ & $\%$ & & \\
\hline \multicolumn{9}{|l|}{ Demographic characteristics } \\
\hline \multicolumn{9}{|l|}{ Sex } \\
\hline Male & 619 & 50.6 & 674 & 49.4 & 1293 & 100.0 & 1 & \\
\hline Female & 619 & 52.0 & 629 & 48.0 & 1248 & 100.0 & $0.97(0.88-1.07)$ & 0.575 \\
\hline \multicolumn{9}{|l|}{ Skin Color } \\
\hline White & 594 & 58.5 & 461 & 41.5 & 1055 & 100.0 & 1 & \\
\hline Non-white & 644 & 45.6 & 842 & 54.4 & 1486 & 100.0 & $1.31(1.18-1.46)$ & $<0.001 *$ \\
\hline \multicolumn{9}{|l|}{ Region in Brazil } \\
\hline North & 250 & 35.9 & 494 & 64.1 & 744 & 100.0 & 1 & \\
\hline Northeast & 349 & 44.2 & 437 & 55.8 & 786 & 100.0 & $0.96(0.74-1.23)$ & 0.731 \\
\hline Midwest & 185 & 63.7 & 118 & 36.3 & 303 & 100.0 & $0.97(0.75-1.25)$ & 0.817 \\
\hline Southeast & 298 & 64.2 & 163 & 35.8 & 461 & 100.0 & $1.49(1.21-1.83)$ & $<0.001 *$ \\
\hline South & 156 & 62.6 & 91 & 37.4 & 247 & 100.0 & $1.71(1.39-2.10)$ & $<0.001 *$ \\
\hline \multicolumn{9}{|l|}{ Area of residence } \\
\hline Urban & 1034 & 54.4 & 946 & 45.6 & 1980 & 100.0 & 1 & \\
\hline Rural & 204 & 38.7 & 357 & 61.3 & 561 & 100.0 & $1.34(1.21-1.50)$ & $<0.001 *$ \\
\hline \multicolumn{9}{|l|}{ Type of residence } \\
\hline State Capital/Metropolitan Region & 825 & 57.2 & 706 & 42.8 & 1531 & 100.0 & 1 & \\
\hline Rural region of the State & 413 & 42.8 & 597 & 57.2 & 1010 & 100.0 & $1.34(1.21-1.48)$ & $<0.001 *$ \\
\hline \multicolumn{9}{|l|}{ Characteristics of access to health services } \\
\hline \multicolumn{9}{|l|}{ Health insurance } \\
\hline Yes & 392 & 65.6 & 206 & 34.4 & 598 & 100.0 & 1 & \\
\hline No & 846 & 46.2 & 1097 & 53.8 & 1943 & 100.0 & $1.56(1.35-1.81)$ & $<0.001 *$ \\
\hline \multirow{2}{*}{\multicolumn{9}{|c|}{$\begin{array}{l}\text { Child's health status as reported by } \\
\text { the respondent }\end{array}$}} \\
\hline & & & & & & & & \\
\hline Very good or good & 1118 & 52.3 & 1129 & 47.7 & 2247 & 100.0 & 1 & \\
\hline Fair, poor or very poor & 120 & 42.6 & 174 & 57.4 & 294 & 100.0 & $1.20(1.05-1.38)$ & $0.008^{*}$ \\
\hline \multicolumn{9}{|l|}{ Last medical appointment } \\
\hline$<1$ Year & 1169 & 52.9 & 1138 & 47.1 & 2307 & 100.0 & 1 & \\
\hline$>1$ Year & 54 & 35.9 & 108 & 64.1 & 162 & 100.0 & $1.36(1.16-1.60)$ & $<0.001 *$ \\
\hline Never & 15 & 21.5 & 57 & 78.5 & 72 & 100.0 & $1.67(1.39-1.99)$ & $<0.001 *$ \\
\hline \multicolumn{9}{|l|}{ Has child ever been to the dentist } \\
\hline Yes & 268 & 60.8 & 184 & 39.2 & 452 & 100.0 & 1 & \\
\hline No & 970 & 49.2 & 1119 & 50.8 & 2089 & 100.0 & $1.30(1.11-1.51)$ & $0.001 *$ \\
\hline \multicolumn{9}{|l|}{ Where is the child's growth monitored } \\
\hline Private or company clinic & 355 & 64.6 & 193 & 35.4 & 548 & 100.0 & 1 & \\
\hline Public hospital, polyclinic or health unit & 784 & 48.9 & 910 & 51.1 & 1694 & 100.0 & $1.45(1.24-1.68)$ & $<0.001 *$ \\
\hline Other & 29 & 39.7 & 40 & 60.3 & 69 & 100.0 & $1.70(1.27-2.29)$ & $<0.001 *$ \\
\hline No follow-up on monitoring & 70 & 34.9 & 160 & 65.1 & 230 & 100.0 & $1.84(1.52-2.23)$ & $<0.001 *$ \\
\hline \multicolumn{9}{|l|}{ Is household registered with Family } \\
\hline \multicolumn{9}{|l|}{ Health Unit } \\
\hline Yes & 709() & 50.1 & 762 & 49.9 & 1471 & 100.0 & 1 & \\
\hline No & 529() & 52.8 & 541 & 47.2 & 1070 & 100.0 & $0.95(0.85-1.05)$ & 0.287 \\
\hline & & & & & & & & continue \\
\hline
\end{tabular}

$\mathrm{PR}=$ prevalence ratio; * $p<0.05 ;$ a Variables with $p<0.25$ in the bivariate analysis or considered epidemiological determinants (such as the sex of the child) were incorporated into the multivariate analysis. 
Bivariate analysis between the characterization of feeding practice and demographic characteristics, access to health services and housing conditions of Brazilian children aged 12-23 months old. Brazil, 2013-2014.

\begin{tabular}{|c|c|c|c|c|c|c|c|c|}
\hline \multirow[t]{3}{*}{ Variables } & \multicolumn{6}{|c|}{ Dietary practice } & \multirow[t]{3}{*}{ PR $R_{\text {Gross }}(\mathrm{Cl} 95 \%)$} & \multirow[t]{3}{*}{ pa } \\
\hline & \multicolumn{2}{|c|}{ Adequate } & \multicolumn{2}{|c|}{ Inadequate } & \multicolumn{2}{|c|}{ Total } & & \\
\hline & $\mathrm{n}$ & $\%$ & $\mathrm{n}$ & $\%$ & $\mathrm{n}$ & $\%$ & & \\
\hline \multicolumn{9}{|l|}{ Have you received visits from a Community } \\
\hline \multicolumn{9}{|l|}{ Health Agent } \\
\hline Yes & 578 & 47.5 & 667 & 52.5 & 1245 & 100.0 & 1 & \\
\hline No & 660 & 55.0 & 636 & 45.0 & 1296 & 100.0 & $0.86(0.77-0.95)$ & $0.003 *$ \\
\hline \multicolumn{9}{|l|}{ Characteristics related to housing conditions } \\
\hline \multicolumn{9}{|l|}{ Number of residents per room } \\
\hline$\leq 0.8$ & 775 & 56.8 & 616 & 43.2 & 1391 & 100.0 & 1 & \\
\hline$>0.8$ & 463 & 43.4 & 687 & 56.6 & 1150 & 100.0 & $1.30(1.19-1.45)$ & $<0.001 *$ \\
\hline \multicolumn{9}{|l|}{ Status of resident at home } \\
\hline Child of parent/guardian and spouse & 842 & 52.7 & 830 & 47.3 & 1672 & 100.0 & 1 & \\
\hline Child or stepchild of parent/guardian & 117 & 47.2 & 127 & 52.8 & 244 & 100.0 & $1.12(0.94-1.32)$ & 0.196 \\
\hline Grandchild or great-grandchild & 248 & 49.4 & 304 & 50.6 & 552 & 100.0 & $1.07(0.95-1.21)$ & 0.274 \\
\hline Other & 31 & 45.4 & 42 & 54.6 & 73 & 100.0 & $1.15(0.88-1.51)$ & 0.306 \\
\hline \multicolumn{9}{|l|}{ Predominant material of house walls } \\
\hline Masonry with cladding + suitable wood & 1093 & 53.3 & 1068 & 46.7 & 2161 & 100.0 & 1 & \\
\hline \multicolumn{9}{|l|}{ Finished wood / straw / rammed earth / } \\
\hline other & 21 & 25.7 & 64 & 74.3 & 85 & 100.0 & $1.59(1.35-1.88)$ & $<0.001$ * \\
\hline Uncoated masonry & 124 & 43.7 & 171 & 56.3 & 295 & 100.0 & $1.21(1.05-1.39)$ & $0.008^{*}$ \\
\hline \multicolumn{9}{|l|}{ Water supply at home } \\
\hline General network & 977 & 54.3 & 877 & 45.7 & 1854 & 100.0 & 1 & \\
\hline \multicolumn{9}{|l|}{ Other (water tank, cistern, well, river, } \\
\hline lake, stream, other) & 261 & 41.8 & 426 & 58.2 & 687 & 100.0 & $1.27(1.15-1.41)$ & $<0.001$ * \\
\hline \multicolumn{9}{|l|}{ Water used for drinking } \\
\hline Treated & 873 & 55.6 & 769 & 44.4 & 1642 & 100.0 & 1 & \\
\hline Untreated & 365 & 42.6 & 534 & 57.4 & 899 & 100.0 & $1.29(1.17-1.43)$ & $<0.001$ * \\
\hline \multicolumn{9}{|l|}{ Residence with kitchen } \\
\hline Yes & 1196 & 51.5 & 1211 & 48.5 & 2407 & 100.0 & 1 & \\
\hline No & 42 & 44.4 & 92 & 55.6 & 134 & 100.0 & $1.15(0.93-1.42)$ & 0.210 \\
\hline \multicolumn{9}{|l|}{ Residence with television } \\
\hline Yes & 1211 & 52.2 & 1216 & 47.8 & 2427 & 100.0 & 1 & \\
\hline No & 27 & 23.6 & 87 & 76.4 & 114 & 100.0 & $1.60(1.38-1.84)$ & $<0.001 *$ \\
\hline \multicolumn{9}{|l|}{ Residence with microwave } \\
\hline Yes & 606 & 62.4 & 382 & 37.6 & 988 & 100.0 & 1 & \\
\hline No & 632 & 43.6 & 921 & 56.4 & 1553 & 100.0 & $1.50(1.34-1.68)$ & $<0.001$ * \\
\hline \multicolumn{9}{|l|}{ Residence with internet access } \\
\hline Yes & 553 & 63.0 & 335 & 37.0 & 888 & 100.0 & 1 & \\
\hline No & 685 & 44.5 & 968 & 55.5 & 1653 & 100.0 & $1.50(1.33-1.69)$ & $<0.001$ * \\
\hline
\end{tabular}

$\mathrm{PR}=$ prevalence ratio; * $p<0.05 ;$ a Variables with $p<0.25$ in the bivariate analysis or considered epidemiological determinants (such as the sex of the child) were incorporated into the multivariate analysis. 
Table 3

Hierarchically adjusted Poisson regression analysis to determine the factors associated with the inadequate dietary practice among Brazilian children aged 12-23 months old. Brazil, 20132014.

\begin{tabular}{|c|c|c|c|c|c|c|c|c|}
\hline \multirow[t]{2}{*}{ Variables } & \multicolumn{2}{|c|}{ Model 1a } & \multicolumn{2}{|l|}{ Model $2^{b}$} & \multicolumn{2}{|l|}{ Model $3 \mathrm{c}$} & \multicolumn{2}{|l|}{ Model 4d } \\
\hline & $\mathrm{PR}_{\text {Adjusted }}(\mathrm{C} 195 \%)$ & $p$ & $\mathrm{PR}_{\text {Adjusted }}(\mathrm{C} 195 \%)$ & $p$ & $\mathrm{PR}_{\text {Adjusted }}(\mathrm{C} 195 \%)$ & $p$ & $\mathrm{PR}_{\text {Adjusted }}(\mathrm{C} 195 \%)$ & $p$ \\
\hline \multicolumn{9}{|l|}{ Block 1} \\
\hline \multicolumn{9}{|l|}{ Demographic characteristics } \\
\hline \multicolumn{9}{|l|}{ Sex } \\
\hline Male & 1 & & 1 & & 1 & & - & - \\
\hline Female & $0.95(0.87-1.95)$ & 0.346 & $0.94(0.86-1.04)$ & 0.242 & $0.95(0.86-1.05)$ & 0.270 & - & - \\
\hline \multicolumn{9}{|l|}{ Skin Color } \\
\hline White & 1 & & 1 & & 1 & & 1 & \\
\hline Non-white & $1.19(1.07-1.33)$ & $0.002^{*}$ & $1.14(1.02-1.27)$ & $0.021^{*}$ & $1.12(1.01-1.25)$ & $0.038^{*}$ & $1.19(1.07-1.33)$ & $0.001 *$ \\
\hline \multicolumn{9}{|l|}{ Region } \\
\hline North & $1.49(1.21-1.84)$ & $<0.001 *$ & $1.40(1.13-1.72)$ & $0.002^{*}$ & $1.35(1.08-1.68)$ & $0.008^{*}$ & $1.46(1.18-1.80)$ & $<0.001^{*}$ \\
\hline Northeast & $1.30(1.06-1.61)$ & $0.013^{*}$ & $1.25(1.01-1.53)$ & $0.038^{*}$ & $1.25(1.01-1.55)$ & $0.046^{*}$ & $1.31(1.07-1.62)$ & $0.010^{*}$ \\
\hline Midwest & $0.89(0.69-1.15)$ & 0.366 & $0.88(0.68-1.14)$ & 0.343 & $0.90(0.69-1.16)$ & 0.401 & $0.89(0.69-1.15)$ & 0.366 \\
\hline Southeast & $0.88(0.69-1.12)$ & 0.303 & $0.89(0.70-1.14)$ & 0.376 & $0.93(0.72-1.19)$ & 0.554 & $0.88(0.69-1.13)$ & 0.317 \\
\hline South & 1 & & 1 & & 1 & & 1 & \\
\hline \multicolumn{9}{|l|}{ Area of residence } \\
\hline Urban & 1 & & 1 & & 1 & & - & - \\
\hline Rural & $1.15(1.03-1.29)$ & $0.014^{*}$ & $1.10(0.98-1.23)$ & 0.121 & $1.03(0.90-1.18)$ & 0.708 & - & - \\
\hline \multicolumn{9}{|l|}{ Type of residence } \\
\hline State Capital/Metropolitan Region & 1 & & 1 & & 1 & & 1 & \\
\hline Rural region in the State & $1.21(1.09-1.35)$ & $<0.001 *$ & $1.15(1.03-1.28)$ & $0.016^{*}$ & $1.12(1.01-1.25)$ & $0.047 *$ & $1.26(1.14-1.38)$ & $<0.001^{*}$ \\
\hline \multicolumn{9}{|l|}{ Block 2} \\
\hline \multicolumn{9}{|c|}{ Characteristics of access to health services: } \\
\hline \multicolumn{9}{|l|}{ Health insurance } \\
\hline Yes & & & 1 & & 1 & & - & - \\
\hline No & & & $1.22(1.01-1.48)$ & $0.044^{*}$ & $1.16(0.95-1.41)$ & 0.139 & - & - \\
\hline \multicolumn{9}{|c|}{ Child's health status as reported by the respondent } \\
\hline Very good or good & & & 1 & & 1 & & - & - \\
\hline Fair, poor or very poor & & & $1.07(0.94-1.22)$ & 0.307 & $1.06(0.92-1.21)$ & 0.417 & - & - \\
\hline
\end{tabular}

PR = prevalence ratio * $p<0.05$ a Model 1 adjusted for individual characteristics (demographic variables): b Model 2 adjusted for individual characteristics (demographic variables and those $\mathrm{PR}=$ prevalence ratio; ${ }^{*} p<0.05 ;$ a Model 1 adjusted for individual characteristics (demographic variables); b Model 2 adjusted for individual characteristics (demographic variables and those
related to access to health services); c Model 3 adjusted for individual and contextual characteristics (demographic variables, related to access to health services and housing conditions);
dModel 4 final. 
Table 3

Hierarchically adjusted Poisson regression analysis to determine the factors associated with the inadequate dietary practice among Brazilian children aged 12-23 months old. Brazil, 2013 2014.

\begin{tabular}{|c|c|c|c|c|c|c|c|c|}
\hline \multirow[t]{2}{*}{ Variables } & \multicolumn{2}{|c|}{ Model 1a } & \multicolumn{2}{|l|}{ Model 2b } & \multicolumn{2}{|l|}{ Model 3c } & \multicolumn{2}{|l|}{ Model 4d } \\
\hline & $\mathrm{PR}_{\text {Adjusted }}(\mathrm{C} 195 \%)$ & $p$ & $\mathrm{PR}_{\text {Adjusted }}(\mathrm{C} 195 \%)$ & $p$ & PR Adjusted $(\mathrm{Cl} 195 \%)$ & $p$ & PR Adjusted (CI95\%) & $p$ \\
\hline \multicolumn{9}{|l|}{ Last medical appointment } \\
\hline$<1$ Year & & & 1 & & 1 & & 1 & \\
\hline$>1$ Year & & & $1.24(1.05-1.47)$ & $0.011 *$ & $1.24(1.05-1.46)$ & $0.012 *$ & $1.26(1.06-1.49)$ & $0.007^{*}$ \\
\hline Never & & & $1.24(1.03-1.48)$ & $0.022 *$ & $1.21(1.02-1.44)$ & $0.031 *$ & $1.33(1.12-1.57)$ & $0.001 *$ \\
\hline \multicolumn{9}{|l|}{ Has child ever been to the dentist } \\
\hline Yes & & & 1 & & 1 & & - & - \\
\hline No & & & $1.10(0.94-1.29)$ & 0.245 & $1.08(0.92-1.26)$ & 0.357 & - & - \\
\hline \multicolumn{9}{|l|}{ Where is the child's growth monitored } \\
\hline Private or company clinic & & & 1 & & 1 & & - & - \\
\hline Public hospital, polyclinic or health unit & & & $1.04(0.86-1.26)$ & 0.694 & $0.96(0.78-1.17)$ & 0.662 & - & - \\
\hline Other & & & $1.03(0.75-1.42)$ & 0.852 & $0.96(0.70-1.31)$ & 0.779 & - & - \\
\hline No follow-up on monitoring & & & $1.17(0.93-1.47)$ & 0.192 & $1.06(0.83-1.34)$ & 0.644 & - & - \\
\hline \multicolumn{9}{|l|}{ Have you received visits from a Community } \\
\hline \multicolumn{9}{|l|}{ Health agent } \\
\hline Yes & & & 1 & & 1 & & - & - \\
\hline No & & & $0.99(0.89-1.09)$ & 0.805 & $0.99(0.90-1.10)$ & 0.937 & - & - \\
\hline \multicolumn{9}{|l|}{ Block 3} \\
\hline \multicolumn{9}{|l|}{ Characteristics related to housing conditions: } \\
\hline \multicolumn{9}{|l|}{ Number of residents per room } \\
\hline$\leq 0.8$ & & & & & 1 & & - & - \\
\hline$>0.8$ & & & & & $1.08(0.98-1.20)$ & 0.134 & - & $\begin{array}{c}- \\
\text { continue }\end{array}$ \\
\hline
\end{tabular}

PR = prevalence ratio: * p<0.05: a Model 1 adjusted for individual characteristics (demographic variables); $b$ Model 2 adjusted for individual characteristics (demographic variables and those related to access to health services): c Model 3 adjusted for individual and contextual characteristics (demographic variables, related to access to health services and housing conditions); dModel 4 final. 
Hierarchically adjusted Poisson regression analysis to determine the factors associated with the inadequate dietary practice among Brazilian children aged $12-23$ months old. Brazil, 2013

2014

\begin{tabular}{|c|c|c|c|c|c|c|c|c|}
\hline \multirow[t]{2}{*}{ Variables } & \multicolumn{2}{|c|}{ Model 1a } & \multicolumn{2}{|l|}{ Model 2b } & \multicolumn{2}{|l|}{ Model 3c } & \multicolumn{2}{|l|}{ Model 4d } \\
\hline & PR Adjusted $(\mathrm{C} 195 \%)$ & $p$ & $\mathrm{PR}_{\text {Adjusted }}(\mathrm{C} 195 \%)$ & $p$ & $\mathrm{PR}_{\text {Adjusted }}(\mathrm{C} 195 \%)$ & $p$ & $\mathrm{PR}_{\text {Adjusted }}(\mathrm{C} 195 \%)$ & $p$ \\
\hline \multicolumn{9}{|l|}{ Predominant material of the house walls } \\
\hline Masonry with cladding + suitable wood & & & & & 1 & & - & - \\
\hline Finished wood / straw / rammed earth / other & & & & & $1.08(0.90-1.28)$ & 0.411 & - & - \\
\hline Unclad masonry & & & & & $1.05(0.92-1.20)$ & 0.474 & - & - \\
\hline \multicolumn{9}{|l|}{ Water supply of residence } \\
\hline General network & & & & & 1 & & - & - \\
\hline Other (water tank, cistern, well, river, & & & & & $1.02(0.91-1.15)$ & 0.735 & _. & - \\
\hline \multicolumn{9}{|l|}{ Water used for drinking } \\
\hline Treated & & & & & 1 & & - & - \\
\hline Untreated & & & & & $1.10(0.99-1.22)$ & 0.083 & - & - \\
\hline \multicolumn{9}{|l|}{ Residence with television } \\
\hline Yes & & & & & 1 & & - & - \\
\hline No & & & & & $1.14(0.99-1.33)$ & 0.078 & - & - \\
\hline \multicolumn{9}{|l|}{ Residence with microwave } \\
\hline Yes & & & & & 1 & & - & - \\
\hline No & & & & & $1.05(0.91-1.21)$ & 0.487 & - & - \\
\hline \multicolumn{9}{|l|}{ Residence with internet access } \\
\hline Yes & & & & & 1 & & - & - \\
\hline No & & & & & $1.12(0.97-1.29)$ & 0.121 & - & - \\
\hline
\end{tabular}

PR = prevalence ratio; * $p<0.05$; a Model 1 adjusted for individual characteristics (demographic variables); b Model 2 adjusted for individual characteristics (demographic variables and those related to access to health services); c Model 3 adjusted for individual and contextual characteristics (demographic variables, related to access to health services and housing conditions); 
Multivariate analysis using the Decision Tree (CHAID) for the feeding practice of Brazilian children aged 12-23 months old adjusted for the investigated factors. Brazil, 2013-2014.

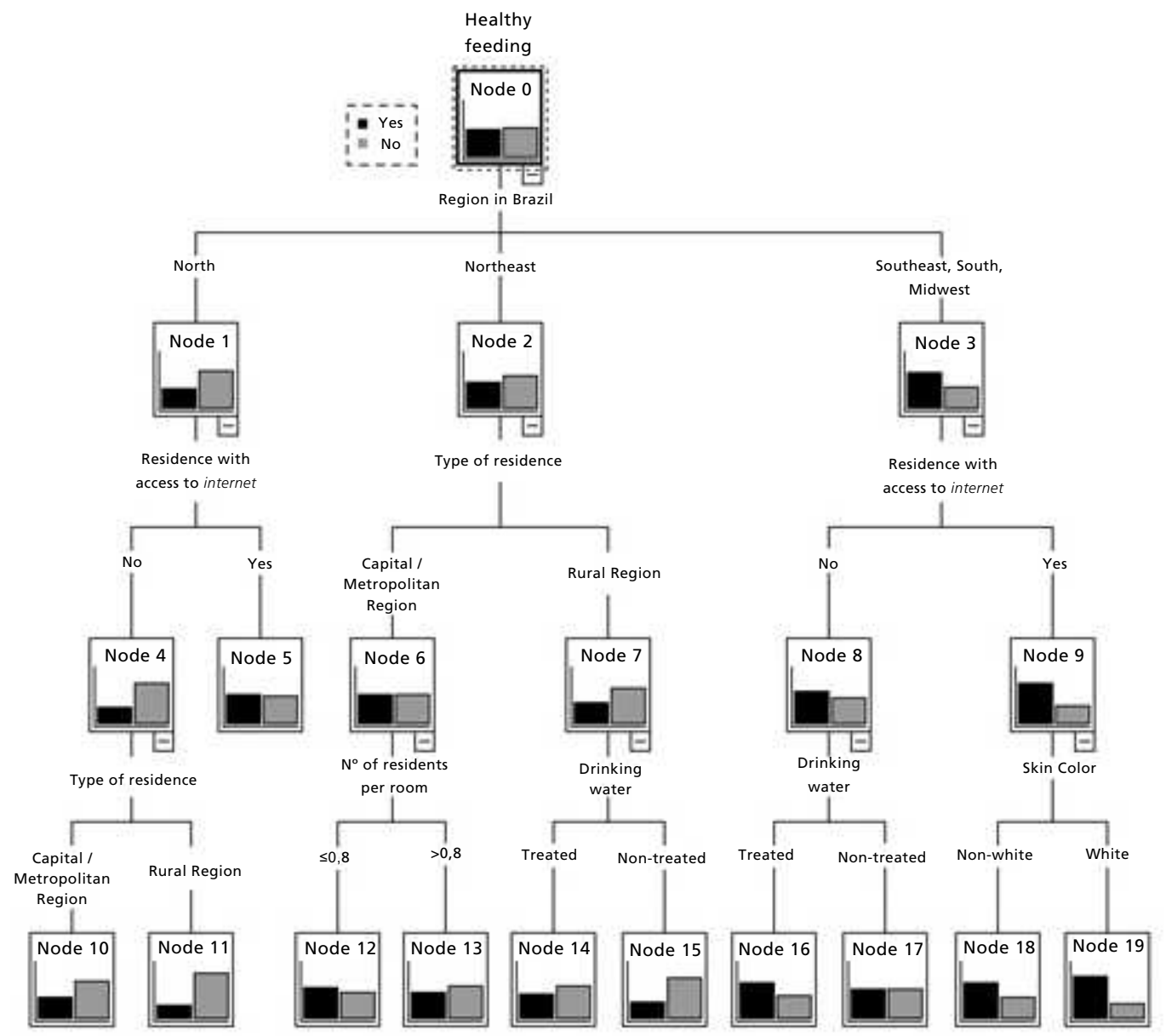

CHAID $=$ Chi-squared Automatic Interaction Detector.

vorable to the child's health, where there is a strong need for qualified care, a strong maternal influence, resulting in unsuitable feeding practices, and to a health model that remains centered on medical actions. ${ }^{23}$ These issues must be addressed to ensure the success of the actions to promote healthy eating at childhood.

In the present study, children who did not attend the appointments for this age group pre-established by the Ministry of Health ${ }^{1}$ were more likely to have inadequate feeding practices, according to Poisson regression. The Ministry of Health recommends seven routine appointments in the first year of life, two in the second, and annual appointments thereafter. The literature shows that the high frequency of children who do not attend the public health service for follow-up care is associated with low maternal education, family structure and the perception that monitoring is unnecessary in the absence of illness. ${ }^{24}$ These results corroborate the findings in the present study, which found an association between a lack of post-birth medical appointments and the inadequate practice of complementary feeding for children aged 12-23 months old.11 Therefore, it is recommended that measures should be adopted to raise awareness of the importance to continue monitoring children's health.

The low frequency of medical appointments for babies is associated with lower maternal education 24 which, in turn, is associated with the quality of food introduction 7,8 Children of mothers with lower levels of education are less likely to have a varied diet and 
more likely to be exposed to unhealthy food (processed juices, soft drinks and sugar or honey). ${ }^{25}$ In addition, mothers face great challenges in feeding their children in the first years of life, resulting from phases of reduced appetite, the child's quest for independence and autonomy, transient "selective feeding" behaviors, 5 as well as a strong maternal influence, resulting in inappropriate feeding practices. 23

It is the responsibility of health professionals to encourage attendance at the appointments to monitor a child's growth and development, even when the mother perceives the child to be healthy 24 and to provide mothers with information and strategies to approach food introduction. 5 In this context, comprehensive awareness programs on healthy feeding that reach all groups in society are essential, especially those that target pregnant women, new mothers and primary caregivers. 4,23

The results of the present study agree with the findings of existing literature 9,10 in revealing that inadequate feeding practices were associated, in both analyzes, with non-white children who lived in the North and Northeast regions, which have the lowest HDIs in Brazil (0.677 and 0.663 respectively26), notably among those living in rural regions outside the large urban centers. Meanwhile, living in the South and Southeast regions, in more socioeconomically developed areas, and being white increased the chances of having adequate feeding practices. These results show that health interventions alone are not enough to promote adequate and healthy feeding. The adoption of measures aimed to reduce social inequalities is of fundamental importance in providing greater opportunities for growth and development for children. 25

Inadequate feeding practices are a public health problem and the role of social determinants must be highlighted. Understanding the factors associated with this condition, which include different environmental and socioeconomic conditions, 27 the cost of healthy food and its influence on access to a quality diet, 6,11 in addition to more economical potential alternatives such as dry grains, ${ }^{28}$ are fundamental for the planning of public policies aimed for this age group, as such knowledge can provide health managers with the support for the implementation of programs focused on diseases prevention in childhood and future adulthood that result from inadequate feeding with nutritional deficiencies, such as obesity, diabetes, heart disease and tooth decay. 4

Cash transfer programs have been found to play an important role in strategies to promote healthy eating 29 with beneficiary families consuming less processed and ultra-processed food in the Southeast and Northeast 29 and greater availability of fresh food and culinary ingredients, 30 particularly in the Northeast, ${ }^{29}$ including food that increase the quality and diversity of the diet. ${ }^{30}$ Measures such as programs to reduce the consumption of sweetened drinks and food, including taxation policies and guidelines for marketing of unhealthy food can also be studied. 4

Limitations of the present study include its cross-sectional design, which prevents the establishment of a causal relation, in addition to the possible bias involved in measuring children's usual diet, due to interviewee memory failure; the lack of detail in the recall questionnaire on the level of processing food, the amount consumed or the frequency of consumption, and the limited validity of the data collection instruments, which are common obstacles in food consumption surveys. However, measures were taken to prevent the occurrence of such problems, such as careful training of the team and in conducting the interviews, supporting the validity of the data. In addition, it is important to emphasize that research based on large samples such as this one have greater precision, which can protect the study from random error.

One of the advantages of this study was the use of national data, compared to others on the same theme which were performed at the regional 8 or city 7 levels, in addition to the selected age group (from 12 to 23 months old), which represents a period of consistency in dietary recommendations. ${ }^{1}$ The use of the Decision Tree Analysis, a Data Mining technique, is also a differentiating factor, as it is relatively new and has been used successfully in epidemiological and public health investigations. ${ }^{17}$

In conclusion, the results of this study show that non-white Brazilian children aged 12 to 23 months old, living in the North and Northeast regions of the country, in towns in the rural areas of the States were more likely to experience inadequate feeding practices, characterized by not fully meeting the food group intake recommended by the Ministry of Health. Measures aimed to improve children's feeding practices must take into account socioeconomic inequalities, different levels of food access and focus on health promotion interventions aimed mainly for families in greater vulnerability.

\section{Authors' contribution}

Rebouças AG, Flório FM and Duarte DA contributed to the study design, Bernardino IM carried out the analysis of the results, Rebouças AG and Flório FM 
contributed to the discussion of the results and to the writing of the manuscript, Dutra ER and Imparato JCP participated in the critical review of the work. All authors approved the final version of the manuscript.

\section{References}

1. Brasil. Ministério da Saúde (MS). Saúde da criança: crescimento e desenvolvimento - Cadernos de Atenção Básica, n. 33. Brasília, DF; 2012

2. WHO (World Health Organization). Sugars intake for adults and children Guideline. Geneva (Switzerland); 2015.

3. Fewtrell M, Bronsky J, Campoy C, Domellöf M, Embleton N, FidlerMis N, Hojsak I, Hulst JM, Indrio F, Lapillonne A, Molgaard C. Complementary Feeding: A Position Paper by the European Society for Paediatric Gastroenterology, Hepatology, and Nutrition (ESPGHAN) Committee on Nutrition. J Pediatr Gastroenterol Nutr. 2017; 64 (1): 11932.

4. Phantumvanit $\mathrm{P}$, Makino $\mathrm{Y}$, Ogawa $\mathrm{H}$, Rugg-Gunn A, Moynihan P, Petersen PE, Evans W, Feldens CA, Lo E, Khoshnevisan MH, Baez R, Varenne B, Vichayanrat T, Songpaisan Y, Woodward M, Nakornchai S, Ungchusak C. WHO Global Consultation on Public Health Intervention against Early Childhood Caries. Community Dent Oral Epidemiol. 2018; 46 (3): 280-7.

5. Skinner JD, Carruth BR, Wendy B, Ziegler PJ. Children's food preferences: a longitudinal analysis. J Am Diet Assoc. 2002; 102: 1638-47.

6. Darmon N, Drewnowski A. Does social class predict diet quality? Am J Clin Nutr. 2008; 87 (5): 1107-17.

7. Sotero AM, Cabral PC, da Silva GAP. Socioeconomic, cultural and demographic maternal factors associated with dietary patterns of infants. Rev Paul Pediatr. 2015; 33 (4): 445-52.

8. Dallazen C, Silva SAD, Gonçalves VSS, Nilson EAF, Crispim SP, Lang RMF, Moreira JD, Tietzmann DC, Vítolo MR. Introduction of inappropriate complementary feeding in the first year of life and associated factors in children with low socioeconomic status. Cad Saúde Pública. 2018 34 (2): e00202816

9. Wen X, Kong KL, Eiden RD, Sharma NN, Xie C. Sociodemographic differences and infant dietary patterns. Pediatrics. 2014; 134 (5): e1387-98

10. Hamner HC, Perrine CG, Gupta PM, Herrick KA, Cogswell ME. Food Consumption Patterns among U.S. Children from Birth to 23 Months of Age, 2009-2014. Nutrients. 2017; 9 (9): 942

11. Victor R, Baines SK, AghoKE, Dibley MJ. Factors associated with inappropriate complementary feeding practices among children aged 6-23 months in Tanzania. Matern Child Nutr. 2014; 10 (4): 545-61.

12. Camara S, de Lauzon-Guillain B, Heude B, Charles MA, Botton J, Plancoulaine S, et al.Multidimensionality of the relationship between social status and dietary patterns in early childhood: longitudinal results from the French
EDEN mother-child cohort. Int J Behav Nutr Phys Act. 2015; $12: 122$

13. Brasil. Ministério da Saúde (MS). Guia alimentar para crianças brasileiras menores de 2 anos. Brasília, DF; 2019.

14. IBGE (Instituto Brasileiro de Geografia e Estatística). Pesquisa Nacional de Saúde - Módulo de Crianças com menos de 2 anos. Nota técnica [Internet]. IBGE; 2013. [acesso em 19 jun 2016]; Disponível em: http://www.pns.icict.fiocruz.br/index.php?pag=resultados

15. IBGE (Instituto Brasileiro de Geografia e Estatística). Diretoria de Pesquisas. Coordenação de Métodos e Qualidade. Pesquisa Nacional de Saúde - Plano amostral. Rio de Janeiro; 2014.

16. Victora CG, Huttly SR, Fuchs SC, Olinto MTA: The role of conceptual frameworks in epidemiological analysis: a hierarquical approach. Int J Epidemiol. 1997; 26: 224-7.

17. Piper ME, Loh WY, Smith SS, JapuntichSJ, Baker TB Using decision tree analysis to identify risk factors for relapse to smoking. Subst Use Misuse. 2011; 46: 492-510.

18. Ye F, Chen ZH, Chen J, Liu F, Zhang Y, Fan QY, Wang L. Chi-squared automatic interaction detection decision tree analysis of risk factors for infant anemia in Beijing, China. Chin Med J. 2016; 129: 1193-9.

19. Louzada MLDC, Ricardo CZ, Steele EM, Levy RB, Cannon G, Monteiro CA. The share of ultra-processed foods determines the overall nutritional quality of diets in Brazil. Public Health Nutr. 2018; 21 (1): 94-102.

20. Brasil. Ministério da Saúde (MS). Secretaria de Atenção à Saúde. Área Técnica de Saúde da Criança e Aleitamento Materno. Rede Amamenta Brasil: os primeiros passos (2007-2010). Brasília, DF; 2011

21. Brasil. Ministério da Saúde (MS). Departamento de Atenção Básica/Secretaria de Atenção à Saúde. Estratégia Nacional para a Alimentação Complementar Saudável. Brasília, DF; 2010.

22. Brasil. Ministério da Saúde (MS). Secretaria de Atenção à Saúde. Estratégia Nacional para Promoção do Aleitamento Materno e Alimentação Complementar Saudável no Sistema Único de Saúde: manual de implementação. Brasília, DF; 2015.

23. Einloft ABN, Cotta RMM, Araujo RMA. Promoção da alimentação saudável na infância: fragilidades no contexto da Atenção Básica. Ciênc Saúde Coletiva. 2018; 23 (1): 6172

24. Vitolo MR, Gama CM, Campagnolo PDB. Frequency of public child care service use and associated factors. J Pediatr. 2010; 86 (1): 80-4.

25. Bortolini GA, Vitolo MR, Gubert MB, Santos LMP. Iniquidades sociais influenciam a qualidade e a diversidade 
da dieta de crianças brasileiras de 6 a 36 meses. Cad Saúde Pública 2015; 31 (11): 2413-24.

26. IPEA (Instituto de Pesquisa Econômica Aplicada) Desenvolvimento humano nas macrorregiões brasileiras. IPEA; 2016.

27. Singh A, Hartford J, Peres MA. Investigating societal determinants of oral health - Opportunities and challenges in multilevel studies. Community Dent Oral Epidemiol. 2018; 00: 1-11.

28. Claro RM, Maia EG, Costa BV, Diniz DP. Food prices in Brazil: prefer cooking to ultra-processed foods. Cad Saúde Pública. 2016; 32 (8): e00104715.

Received on October 1, 2019

Final version presented on July 19, 2020

Approved on August 31, 2020
29. Sperandio N, Rodrigues CT, Franceschini SDCC, Priore SE. The impact of the Bolsa Família Program on food consumption: a comparative study of the southeast and northeast regions of Brazil. Ciênc Saúde Coletiva. 2017; 22 (6): 1771-80.

30. Martins APB, Monteiro CA. Impact of the Bolsa Familia program on food availability of low-income Brazilian families: a quasi experimental study. BMC Public Health. 2016; 16: 827 . 